\title{
Resection of a staggering 36-cm angiomyolipoma
}

\author{
Bishoy A. Gayed, MD; Bruce L. Jacobs, MD; Erin P. Gibbons, MD; Ronald L. Hrebinko, MD
}

\begin{abstract}
Angiomyolipomas (AMLs) are benign tumours characterized by fat, smooth muscle and vascular components. Epithelioid AML is a recognized variant of $A M L$ that is comprised of epithelioid smooth muscle cells. We present a case of a 41-year-old male who presented with light-headedness, dizziness, right-sided abdominal pain and, on subsequent computed tomography, was found to have an enormous right kidney mass characteristic of an AML. The patient underwent preoperative selective arterial embolization followed by a right radical nephrectomy. The pathology revealed a 36-cm AML with focal epithelioid features. Although uncommon, AMLs can present as enormous retroperitoneal masses.
\end{abstract}

Can Urol Assoc J 2010;4(4):E97-99

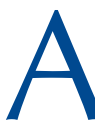
41-year-old healthy male with a recent history of syncope presented with complaints of persistent lightheadedness, dizziness and right-sided abdominal pain. At an outside hospital, he received 2 units of packed red blood cells for his anemia, and a computed tomography (CT) scan of his abdomen and pelvis revealed an enormous right renal mass with multiple vascular and adipose-laden areas characteristic of an angiomyolipoma (AML) (Fig. 1). The patient was subsequently transferred to our hospital for further management.

Upon arrival, the patient's blood pressure was stable, but he was tachycardic with a heart rate in the 110 range. He had an otherwise unremarkable medical and family history, with no clinical stigmata typical of tuberous sclerosis. On examination, he was moderately obese with a large palpable right-sided abdominal mass. His creatinine was $1.1 \mathrm{mmol} / \mathrm{L}$. His presenting hematocrit of $21 \%$ led to an additional transfusion of 1 unit of packed red blood cells; he was immediately sent to interventional radiology for an angiogram and embolization to obtain hemostasis and, by embolizing most of the tumour's blood supply, to reduce the risk of intraoperative hemorrhage. The angiogram revealed a large hypervascular tumour supplied predominantly from a right superior pole renal artery and its branches; these were all embolized and the post-procedure angiogram showed a significant reduction in the lesion's vascularity.

The patient's hematocrit continued to drop overnight to $19 \%$; he received an additional 2 units of packed red blood cells and returned to interventional radiology for further evaluation. On angiogram, a 3-cm pseudoaneurysm (Fig. 2) from another branch of the right renal artery was found and embolized proximal to it. In addition, one of the branches of the renal artery, that was embolized the day before, continued to have flow and was re-embolized. The post-embolization angiogram showed stasis of flow both to the pseudoaneurysm and the re-embolized vessel. Subsequently, his hematocrit stabilized at $26 \%$.

The following day, the patient underwent a right radical nephrectomy through a thoracoabdominal incision. The tumour did not invade any adjacent organs and weighed $7.6 \mathrm{~kg}$ when it was removed (Fig. 3). The pathology revealed a $36 \times 25 \times 18 \mathrm{~cm}$ angiomyolipoma with focal epithelioid areas. The patient was discharged on postoperative day 7 , had an unremarkable follow-up appointment 2 weeks later, and is scheduled for a repeat CT scan in 1 year.

\section{Discussion}

Renal AMLs are rare benign tumours composed of variable amounts of fat, smooth muscle and thick-walled blood vessels. ${ }^{1,2}$ An autosomal disorder, tuberous sclerosis consists of a syndrome of epilepsy, mental retardation and adneoma sebaceum. Commonly associated with these patients are AMLs, which occur in roughly in $40 \%$ to $80 \%$ of these patients. ${ }^{3}$ However, $80 \%$ of patients with AMLs do not have tuberous sclerosis. ${ }^{4}$ Generally, AMLs are detected by CT scan, which reveals a mass with high fat content as measured by negative Hounsfield units and vascular components. ${ }^{4}$ Once AMLs are discovered, their size and symptoms determine the treatment because of the differences in the likelihood of hemorrhage. ${ }^{5}$ As stated by Oesterling and colleagues and Steiner and colleagues, among others, tumours greater than $4 \mathrm{~cm}$ are more likely to be symptomatic and to hemorrhage, requiring embolization and/or surgery. ${ }^{6,7}$ Given 


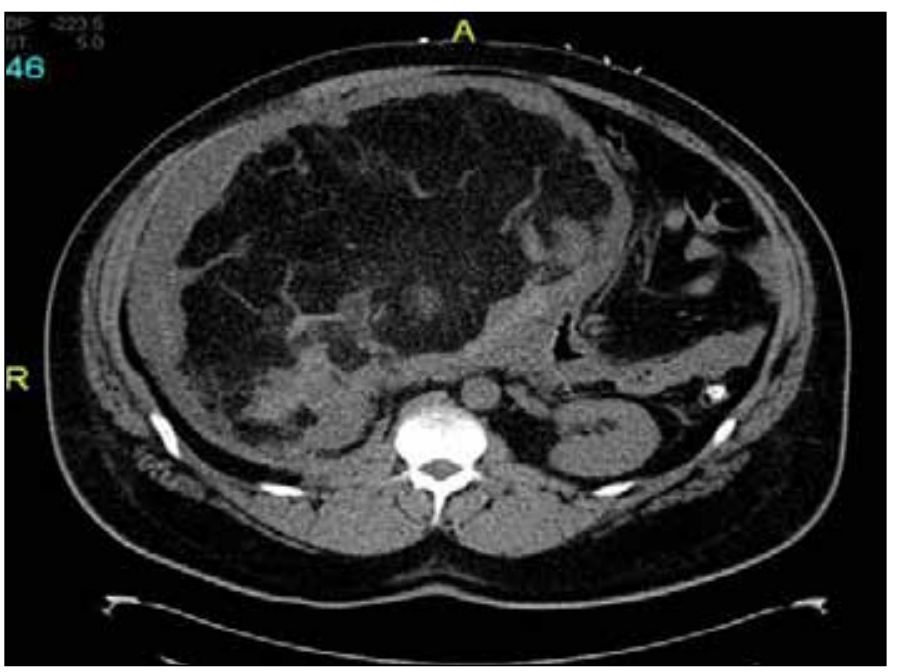

Fig. 1. Mass revealed on computed tomography scan.

the benign nature of AMLs, selective arterial embolization or renal sparing surgery is the first choice. In this case, the patient was symptomatic with a low hematocrit and hemorrhage from the lesion on angiogram, which necessitated an immediate intervention. Embolization was done to control the patient's immediate hemorrhage and to reduce the risk of intraoperative bleeding. This lesion was too large to attempt a partial nephrectomy, especially given that the patient was otherwise healthy with a normal contralateral kidney. Another concern raised by the enormous size of this lesion was that this could be a liposarcoma. Retroperitoneal liposarcomas are generally large with nearly $50 \%$ being larger than $20 \mathrm{~cm}$ at diagnosis; they are composed predominantly of adipose tissue and can occasionally be hard to differentiate from AMLs on imaging. ${ }^{8,9}$ Making a distinction between

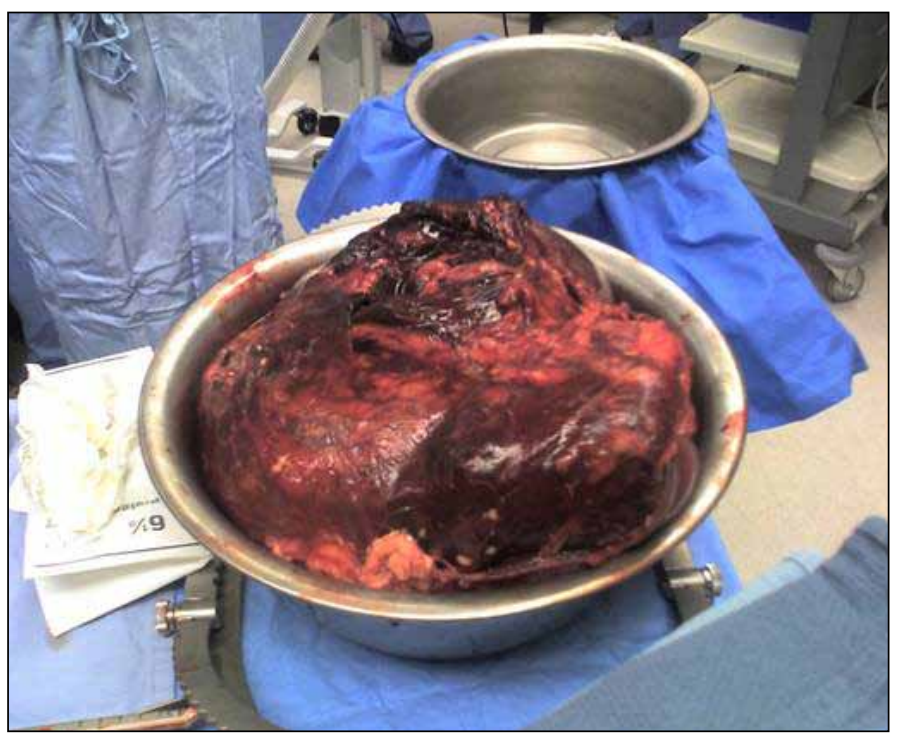

Fig. 3. Specimen.

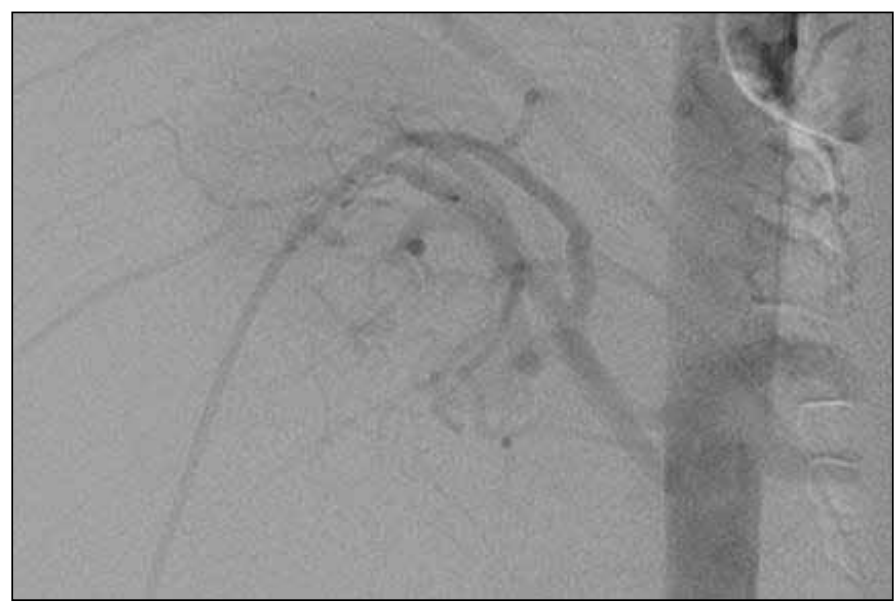

Fig. 2. Vessels supplying the lesion on angiogram.

them, however, is imperative because liposarcomas have a much worse prognosis. ${ }^{8,9}$

After complete resection, the pathology of this tumour revealed a 36-cm AML with focal epithelioid areas weighing $7.6 \mathrm{~kg}$. The mass invaded the kidney and the surgical margins were negative. Epithelioid $\mathrm{AML}$ is a recognized variant of AML, which is characterized by the presence of epithelioid smooth muscle cells. ${ }^{10}$ The expression of melanocyte markers and smooth muscle cell markers has standardized the histological diagnosis of epithelioid AML and, in our case, immunohistochemical staining was positive for actin, HMB-45, melan-A, and c-kit, all of which supported this diagnosis. ${ }^{10,11}$ Although only focal epithelioid areas were noted, the decision was made to obtain a follow-up CT scan in 1 year given the potentially aggressive nature of this feature. ${ }^{4,12}$

\section{Conclusion}

This case is an example of an enormous AML. Management included preoperative embolization followed by radical nephrectomy; our recommended follow-up was based on the lesion's focal epithelioid features.

Department of Urology, University of Pittsburgh School of Medicine, Pittsburgh, PA

Competing interests: None declared.

This paper has been peer-reviewed. 


\section{References}

1. Fischer W. Die nierentumoren bei der tuberosen hirnsklerose [in German]. Ziegler Beitr Path Ant Allg Pathol 1911:50:235.

2. Bret PM, Bretagnolle M, Gaillard D, et al. Small, asymptomatic angiomyolipomas of the kidney. Radiology 1985;154:7-10.

3. Glassbery K, Renal dysgensis and cystic disease of the kidney. In: Wein AJ, Kavoussi LR, Novick AC, Partin AW, Peters CA, eds. Campbells-Walsh Urology. 9th edition. Philadelphia, PA: Saunders-Elsevier; 2007:3329-31.

4. Martignoni G, Pea M, Bonetti F, et al. Carcinomalike monotypic epithelioid angiomyolipoma in patients without evidence of tuberous sclerosis: a clinicopathologic and genetic study. Am I Surg Pathol 1998;22:663-72.

5. Dickinson $M$, Ruckle $H$, Beaghler $M$, et al. Renal angiomyolipoma: optimal treatment based on size and symptoms. Clin Nephrol 1998;49:281-6.

6. Steiner MS, Goldman SM, Fishman EK, et al. The natural history of renal angiomyolipoma. J Urol 1993;150:1782-6.
7. Oesterling JE, Fishman EK, Goldman SM, et al. The management of renal angiomyolipoma. J Urol 1986;135:1121-4.

8. Chouairy CJ, Abdu-Karim FW, Maclennan GT. Retroperitoneal liposarcoma. J Urol 2007;177:1145.

9. Israel GM, Bosniak MA, Slywotsky CM, et al. CT differentiation of large exophytic renal angiomyolipomas and perirenal liposarcomas. AJR Am J Roentgenol 2002;179:769-73.

10. Pea M, Bonetti F, Zamboni $G$, et al. Melanocyte-marker HMB-45 is regularly expressed in angiomyolipoma of the kidney. Pathology 1991;23:185-8.

11. Acikalin MF, Tel N, Oner U, et al. Epithelioid angiomyolipoma of the kidney. Int J Urol 2005;12:204-7.

12. Park HK, Zhang S, Wong MK, et al. Clinical presentation of epithelioid angiomyolipoma. Int I Urol 2007;14:21-5.

Correspondence: Dr. Bishoy A. Gayed, Department of Urology, University of Pittsburgh School of Medicine, 3471 Fifth Ave., Suite 700, Pittsburgh, PA 15213; gayedb@upmc.edu 